\title{
Multiple mechanisms of MYCN dysregulation in Wilms tumour
}

\author{
Richard D. Williams ${ }^{1}$, Tasnim Chagtai ${ }^{1}$, Marisa Alcaide-German ${ }^{1}$, John Apps ${ }^{1}$, Jenny \\ Wegert $^{2}$, Sergey Popov ${ }^{3}$, Gordan Vujanic ${ }^{4}$, Harm van Tinteren ${ }^{5}$, Marry M van den \\ Heuvel-Eibrink ${ }^{6}$, Marcel Kool ${ }^{7}$, Jan de Kraker ${ }^{8}$, David Gisselsson ${ }^{9}$, Norbert Graf ${ }^{10}$, \\ Manfred Gessler ${ }^{2}$ and Kathy Pritchard-Jones ${ }^{1}$ \\ ${ }^{1}$ UCL Institute of Child Health, 30 Guilford Street, London, UK \\ 2 Theodor-Boveri-Institute/Biocenter, Developmental Biochemistry and Comprehensive Cancer Center Mainfranken, \\ Wuerzburg University, Wuerzburg, Germany \\ ${ }^{3}$ Institute of Cancer Research, Sutton, Surrey, UK \\ ${ }^{4}$ Cardiff University School of Medicine, Heath Park, Cardiff, UK \\ ${ }^{5}$ Biometrics Department, Netherlands Cancer Institute, Antonie van Leeuwenhoek Ziekenhuis, Amsterdam, The Netherlands \\ ${ }^{6}$ Department of Pediatric Oncology/Hematology, Erasmus MC, Sophia Children's Hospital, Rotterdam, The Netherlands \\ ${ }^{7}$ German Cancer Research Centre, Heidelberg, Germany \\ ${ }^{8}$ Academic Medical Center, Amsterdam, The Netherlands \\ 9 Department of Clinical Genetics, Lund University, Sweden \\ ${ }^{10}$ Department of Paediatric Oncology and Haematology, Saarland University Hospital, Homburg/Saar, Germany \\ Correspondence to: Richard D. Williams, email: richard.williams@ucl.ac.uk
}

Keywords: Wilms tumour, MYCN, copy number, DNA methylation, prognostic marker

Received: August 08, $2014 \quad$ Accepted: January 14, $2015 \quad$ Published: January 31, 2015

This is an open-access article distributed under the terms of the Creative Commons Attribution License, which permits unrestricted use, distribution, and reproduction in any medium, provided the original author and source are credited.

\section{ABSTRACT}

Genomic gain of the proto-oncogene transcription factor gene $M Y C N$ is associated with poor prognosis in several childhood cancers. Here we present a comprehensive copy number analysis of MYCN in Wilms tumour (WT), demonstrating that gain of this gene is associated with anaplasia and with poorer relapse-free and overall survival, independent of histology. Using whole exome and gene-specific sequencing, together with methylation and expression profiling, we show that $M Y C N$ is targeted by other mechanisms, including a recurrent somatic mutation, $P 44 L$, and specific DNA hypomethylation events associated with MYCN overexpression in tumours with high risk histologies. We describe parallel evolution of genomic copy number gain and point mutation of $\mathbf{M Y C N}$ in the contralateral tumours of a remarkable bilateral case in which independent contralateral mutations of TP53 also evolve over time. We report a second bilateral case in which $M Y C N$ gain is a germline aberration. Our results suggest a significant role for $M Y C N$ dysregulation in the molecular biology of Wilms tumour. We conclude that $M Y C N$ gain is prognostically significant, and suggest that the novel P44L somatic variant is likely to be an activating mutation.

\section{INTRODUCTION}

Wilms tumour (WT, nephroblastoma) is the commonest paediatric renal malignancy. A significant minority of WT cases have mutations in known genes, including WT1 [1-6], CTNNB1 [7, 8], AMER1 (WTX) [9], and TP53 [10]. Less frequent mutations targeting genes such as FBXW7 [11] and GPC3 [12] have also been reported, and epigenetic lesions affecting the IGF2/
H19 locus are common [13]. A recent whole exome study has indentified mutations in microRNA processing genes including DROSHA, DGCR8 and DICER1 [14]. Numerous recurrent copy number aberrations and loss of heterozygosity ( $\mathrm{LOH}$ ) events have been described, some of which affect known genes (e.g. 11p LOH, 17p loss, focal deletion of AMERI and FBXW7), while the functional significance of others (e.g. 1q gain, 1p loss, $16 q$ loss) is unclear. Only a few of these aberrations have 
known associations with histology or outcome. TP53 mutations are largely confined to (high risk) anaplastic tumours [10], while WT1 mutations (which are frequently coincident with CTNNB1 mutations) are associated with stromal predominant histology [15]. We have previously noted an association between 1q gain and relapse [16, 17], but the only genomic biomarker with a fully validated association with poor outcome that is currently used in treatment planning is simultaneous loss of heterozygosity of $1 \mathrm{p}$ and $16 \mathrm{q}$ [18].

One recurrent focal copy number gain on $2 \mathrm{p} 24.3$, encompassing the $M Y C N$ locus, has been observed in several previous WT studies [11, 19-23]. The $M Y C N$ gene encodes a proto-oncogenic MYC family transcription factor, MYCN. MYCN is known to be amplified in 16$25 \%$ of neuroblastomas, an aberration associated with a poorer prognosis, and it undergoes prognostically relevant copy number gain, and more rarely amplification, in other paediatric tumours including medulloblastoma [24, 25] and rhabdomyosarcoma [26]. In an earlier study [11], we used SNP arrays to analyse tumours from patients who had received pre-operative chemotherapy under International Society of Paediatric Oncology (SIOP) protocols, and noted an apparent association between $M Y C N$ gain and the high risk diffuse anaplastic subtype. In a larger study [22], in which genomic real-time PCR was used to measure $M Y C N$ copy number in a more heterogenous group of tumours from patients treated under various protocols (including immediate nephrectomy), we confirmed that MYCN gain is a common event, but found no particular subtype association. In the current report, we describe the largest analysis of MYCN status in WT to date, using multiplex ligation dependent probe amplification (MLPA) to assess its copy number in a series of samples drawn entirely from the SIOP WT 2001 clinical study and trial.

Recent developments in neuroblastoma genomics suggest that gain or amplification is not the only mechanism that affects MYCN function in paediatric tumours. Maris and co-workers, using whole genome sequencing, have shown that a specific somatic variant, P44L, can be detected in $2 \%$ of all neuroblastomas analysed [27], while isolated cases of the same variant have also been described in glioma, medulloblastoma, endometrial carcinoma, and neoplastic cysts of the pancreas [28-31]. This variant is postulated to be an activating 'gain of function' mutation that, like increased MYCN dosage due to copy number gain, could cause oncogenic upregulation of downstream MYCN-dependent pathways.

Here we report the discovery of $M Y C N$ P44L mutations through whole exome analysis of Wilms tumour, leading us to hypothesise that multiple routes to MYCN-oncogenesis may exist in this paediatric tumour. We present targeted $M Y C N$ sequencing analysis of a large WT series to determine the frequency of these mutations, and investigate potential correlations between $M Y C N$ expression levels, copy number events, and gene-specific hypomethylation.

\section{RESULTS}

\section{Point mutations in the MYCN coding sequence}

In a whole exome analysis of a series of $51 \mathrm{WTs}$, enriched in cases with high risk histology or poor outcome, heterozygous somatic point mutations in the $M Y C N$ coding sequence were detected in three tumours. In all three cases, the same variant, a c. $131 \mathrm{C}>\mathrm{T}$ transition substituting proline with leucine at codon 44 (p.P44L), was detected (Table 1). 45 of the 51 cases gave informative exome data at this position, with sufficient depth of coverage for variant calling. Thus, $6.7 \%$ of the cases that could be analysed in the exome series carried this mutation. To determine the proportion of WTs harbouring this or other MYCN mutations in a larger, unselected cohort (Supplementary Table 1), we sequenced the complete MYCN coding region in 168 additional tumour samples. Where a mutation was detected, we sequenced matched normal kidney or blood germline DNA (if available) from the same case. Five additional tumours carrying P44L were identified $(3.0 \%$, Table 1$)$ and, as in the exome series, all mutations were heterozygous in the tumour and absent from the germline. The overall frequency of P44L in the extended series of 213 cases was therefore $3.8 \%$. The subset carrying the mutation had no particular distinguishing features. Multiple histological subtypes (as defined by SIOP) and clinical stages were represented (Table 1). Only one of the patients - the complex bilateral case described in Table 2 and below - has so far suffered a recurrence (minimum follow-up 25 months, median follow-up 54.5 months), and none have died.

Four further non-synonymous heterozygous variants elsewhere in the $M Y C N$ coding sequence, each affecting a single case, were also found (Table 1). The first of these, c. $853 \mathrm{C}>\mathrm{T}$ (p.R285W), was present in the germline. R285 is a highly conserved amino acid residue in protein domain pfam01056 ('Myc amino-terminal region' [32]). This mutation was predicted as damaging by both SIFT [33] and PolyPhen2 [34]. The second variant, c.227G $>$ A (p.S76N), was found in a case for which no blood or unambiguous normal kidney tissue was available, so it was not possible to determine if it was a germline variant. S76 is a poorly conserved residue, and the $\mathrm{S} 76 \mathrm{~N}$ variant was not predicted as damaging by either SIFT or PolyPhen. A third variant, c.473C $>$ T (p.A158V), was located in another poorly conserved region and predicted as tolerated by SIFT, but possibly damaging by PolyPhen, and was confirmed as present in the germline. The fourth variant, c.1093C $>$ G (p.P365A), was also predicted to be a benign change by both algorithms, and is a known rare variant 
Table 1: MYCN single nucleotide variants in Wilms tumour.

\begin{tabular}{|c|c|c|c|c|c|c|c|c|c|c|c|c|c|}
\hline ICH ID & Exome & Genomic (Chr2) & CDS & Protein & Germline & ESP5400 & $1000 \mathrm{~g}$ & dbSNP 132 & SIFT & $\begin{array}{l}\text { Poly- } \\
\text { Phen2 }\end{array}$ & Histology & Stage & MYCN CN \\
\hline 2560 & Y & g. $16082317 \mathrm{C}>\mathrm{T}$ & c. $131 \mathrm{C}>\mathrm{T}$ & p.P44L & Wild type & & & & D & D & Focal Anaplastic & 3 & Normal \\
\hline 3863 & Y & g. $16082317 \mathrm{C}>\mathrm{T}$ & c. $131 \mathrm{C}>\mathrm{T}$ & p.P44L & Wild type & & & & D & D & Regressive & 1 & Normal \\
\hline 4788 & & g. $16082317 \mathrm{C}>\mathrm{T}$ & c. $131 \mathrm{C}>\mathrm{T}$ & p.P44L & Wild type & & & & D & D & Regressive & 3 & Gain \\
\hline 4956 & & g. $16082317 \mathrm{C}>\mathrm{T}$ & c. $131 \mathrm{C}>\mathrm{T}$ & p.P44L & Wild type & & & & D & D & Regressive & 2 & Normal \\
\hline 6613 & & g. $16082317 \mathrm{C}>\mathrm{T}$ & c. $131 \mathrm{C}>\mathrm{T}$ & p.P44L & Wild type & & & & D & $\mathrm{D}$ & Mixed & 1 & Gain \\
\hline 8783 & $\mathrm{Y}$ & g. $16082317 \mathrm{C}>\mathrm{T}$ & c. $131 \mathrm{C}>\mathrm{T}$ & p.P44L & Wild type & & & & D & D & Blastemal & 2 & Normal \\
\hline 8819 & & g. $16082317 \mathrm{C}>\mathrm{T}$ & c. $131 \mathrm{C}>\mathrm{T}$ & p.P44L & Wild type & & & & D & D & Regressive & 3 & Gain \\
\hline 9750 & & g. $16082317 \mathrm{C}>\mathrm{T}$ & c. $131 \mathrm{C}>\mathrm{T}$ & p.P44L & Wild type & & & & D & $\mathrm{D}$ & Mixed & 1 & Normal \\
\hline 3136 & & g. $16085677 \mathrm{C}>\mathrm{T}$ & c. $853 \mathrm{C}>\mathrm{T}$ & p.R285W & Variant & & & & D & D & Stromal & 1 & Normal \\
\hline 4692 & & g. $16082413 \mathrm{G}>\mathrm{A}$ & c. $227 \mathrm{G}>\mathrm{A}$ & p.S76N & N/A & & & & $\mathrm{T}$ & B & Regressive & 3 & Normal \\
\hline 7512 & & g. $16082659 \mathrm{C}>\mathrm{T}$ & c. $473 \mathrm{C}>\mathrm{T}$ & p.A158V & Variant & & & & $\mathrm{T}$ & $\mathrm{P}$ & Stromal & 2 & Gain \\
\hline 9431 & & g. $16085917 \mathrm{C}>\mathrm{G}$ & c. $1093 \mathrm{C}>\mathrm{G}$ & p.P365A & N/A & 0.0005 & 0.0005 & & $\mathrm{~T}$ & B & Regressive & 3 & Normal \\
\hline 8914 & & g. $16082375 C>A$ & c. $189 \mathrm{C}>\mathrm{A}$ & p.P63P & ND & & & & - & - & Mixed & 1 & Gain \\
\hline 9140 & & g. $16082393 \mathrm{G}>\mathrm{A}$ & c. $207 \mathrm{G}>\mathrm{A}$ & p.E69E & ND & 0.0027 & 0.0009 & rs41264199 & - & - & Regressive & 1 & Normal \\
\hline 9224 & & g. $16082393 \mathrm{G}>A$ & c. $207 \mathrm{G}>\mathrm{A}$ & p.E69E & ND & 0.0027 & 0.0009 & rs41264199 & - & - & Regressive & 1 & Normal \\
\hline
\end{tabular}

SIFT/PolyPhen2: $\mathrm{D}=$ damaging, $\mathrm{T}=$ tolerated, $\mathrm{B}=$ benign, $\mathrm{P}=$ possibly damaging. $1000 \mathrm{~g}=$ variant frequency in 1000 Genome Project (Feb 2012). ESP5400 = variant frequency in Exome Sequencing Project (Dec 2011). N/A = material not available. $\mathrm{ND}=$ Not done.

previously observed in the 1000 Genome Project data [35]. Data from unambiguous germline material were not available. No congenital abnormalities or family history of cancer were reported in three of these cases; no data were available for the A158V case. Two further variants
(c.189C $>$ A, c. $207 \mathrm{G}>\mathrm{A}$ ), one of which was a rare known SNP, were also identified in three samples (Table 1), but they did not alter the amino acid sequence or overlap with splice sites and were not analysed further.

MLPA copy number analysis of all the cases with

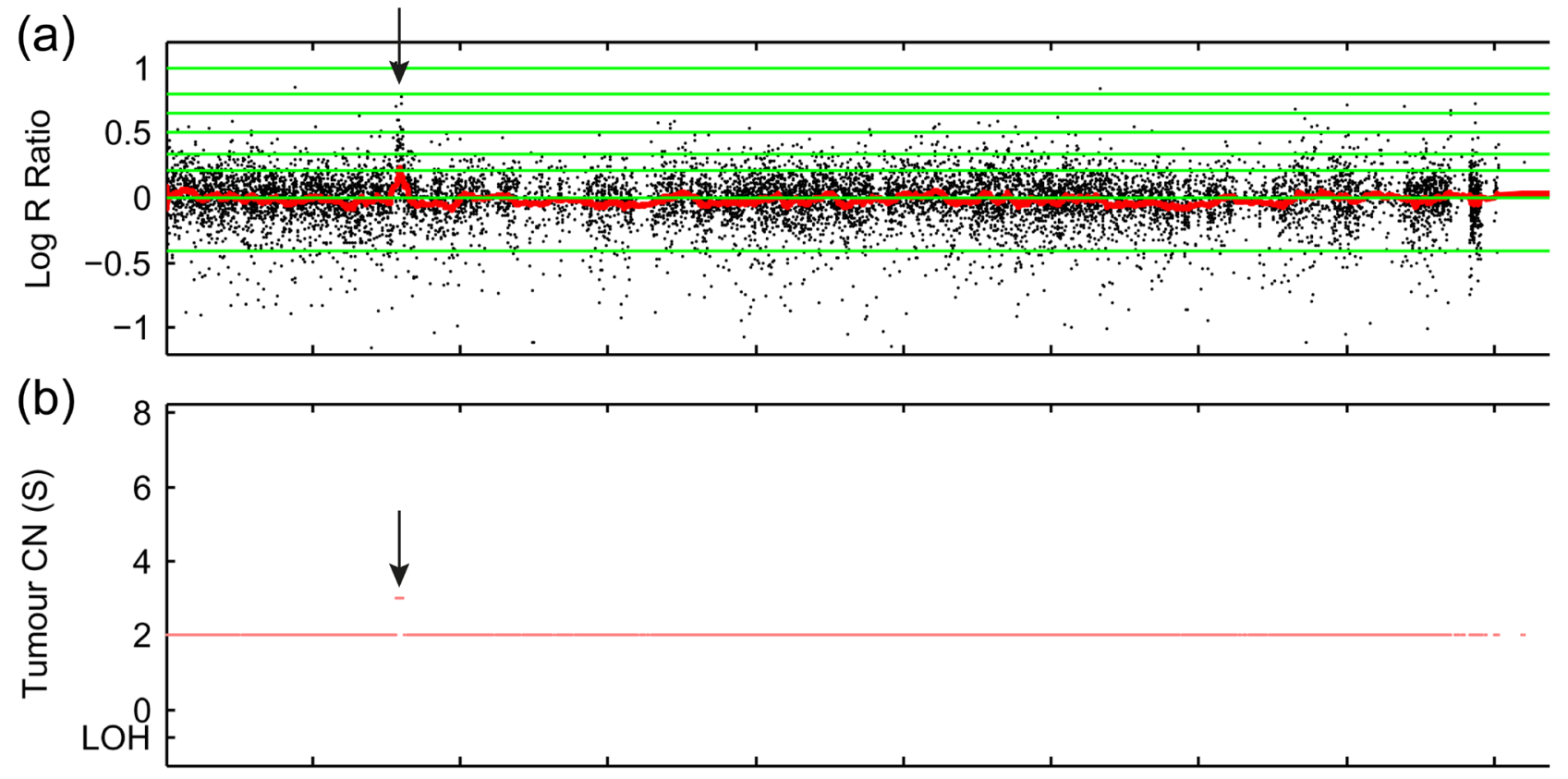

Figure 1: Focal gain of $M Y C N$ in the germline of a bilateral WT case. (a) Illumina CytoSNP-12 raw copy number data (Log R Ratio) from blood sample ICH-10529 showing probes aligned to the $2 p$ region. (b) Copy number segmentation by OncoSNP (linear scale). Arrows: position of region of focal gain. $\mathrm{LOH}=$ segmented loss of heterozygosity (none detected). 
Table 2: MYCN and TP53 aberrations in a bilateral WT case.

\begin{tabular}{|c|c|c|c|c|c|c|c|c|}
\hline $\begin{array}{l}\text { ICH } \\
\text { ID } \\
\end{array}$ & Side & Sample & Histology & TP53 & MYCN seq data & \begin{tabular}{|l|}
$\mathrm{MYCN}$ \\
$\mathrm{CN}$ \\
\end{tabular} & $\begin{array}{l}\text { Other } \\
\text { aberrations } \\
\end{array}$ & \begin{tabular}{|l|} 
Treatment \\
Month \\
\end{tabular} \\
\hline 5179 & & Blood & & wild type & wild type & NA & NA & \\
\hline 3474 & Left & Initial biopsy & Wilms tumour & wild type & ND & Gain & $\begin{array}{l}+1 \mathrm{q},+6,+8,-10 \mathrm{p} \\
+12 \mathrm{p},+13,-20 \mathrm{p}\end{array}$ & 1 \\
\hline 6583 & Left & $\begin{array}{l}\text { Partial } \\
\text { nephrectomy }\end{array}$ & $\begin{array}{l}\text { Wilms tumour } \\
\text { (stromal area) }\end{array}$ & wild type & wild type & NA & NA & 6 \\
\hline 6580 & Left & $\begin{array}{l}\text { Partial } \\
\text { nephrectomy }\end{array}$ & $\begin{array}{l}\text { Wilms tumour } \\
\text { (anaplastic area) }\end{array}$ & $\begin{array}{l}\text { c. } 517 \mathrm{G}>\mathrm{T}: \\
\text { p. } 173 \mathrm{~V}>\mathrm{L}\end{array}$ & wild type & NA & NA & 6 \\
\hline 3864 & Left & $\begin{array}{l}\text { Partial } \\
\text { nephrectomy }\end{array}$ & $\begin{array}{l}\text { Wilms tumour } \\
\text { (diffuse anaplastic) }\end{array}$ & $\begin{array}{l}\text { c. } 517 \mathrm{G}>\mathrm{T}: \\
\text { p. } 173 \mathrm{~V}>\mathrm{L}\end{array}$ & wild type & Gain & $\begin{array}{l}+2,+6,-10 p,+13 \\
-14 q,-17 p,+17 q \\
-20 p\end{array}$ & 6 \\
\hline 3865 & Left & $\begin{array}{l}\text { Partial } \\
\text { nephrectomy }\end{array}$ & $\begin{array}{l}\text { Wilms tumour } \\
\text { (diffuse anaplastic) }\end{array}$ & $\begin{array}{l}\text { c. } 517 \mathrm{G}>\mathrm{T}: \\
\text { p. } 173 \mathrm{~V}>\mathrm{L}\end{array}$ & wild type & Gain & $\begin{array}{l}+2, \text { LOH } 6,+8 \\
-10 p,+10 q,+13 \\
-17 p,+17 q,-20 p\end{array}$ & 6 \\
\hline 6579 & Left & $\begin{array}{l}\text { Partial } \\
\text { nephrectomy }\end{array}$ & Normal kidney & wild type & wild type & NA & NA & 6 \\
\hline 6578 & Left & $\begin{array}{l}\text { Partial } \\
\text { nephrectomy }\end{array}$ & Nephrogenic rest & wild type & wild type & NA & NA & 6 \\
\hline 3475 & Right & Initial biopsy & Wilms tumour & wild type & wild type & Normal & Neutral profile & 1 \\
\hline 6581 & Right & $\begin{array}{l}\text { Partial } \\
\text { nephrectomy }\end{array}$ & $\begin{array}{l}\text { Wilms tumour } \\
\text { (regressive) }\end{array}$ & wild type & c.C131T:p.P44L & NA & NA & 6 \\
\hline 3863 & Right & $\begin{array}{l}\text { Partial } \\
\text { nephrectomy }\end{array}$ & $\begin{array}{l}\text { Wilms tumour } \\
\text { (regressive) }\end{array}$ & wild type & c.C131T:p.P44L & Normal & $+1 \mathrm{q}, \mathrm{LOH} 14$ & 6 \\
\hline 6582 & Right & $\begin{array}{l}\text { Partial } \\
\text { nephrectomy }\end{array}$ & Normal kidney & wild type & wild type & NA & NA & 6 \\
\hline 9934 & Right & $\begin{array}{l}\text { Partial } \\
\text { nephrectomy }\end{array}$ & Nephrogenic rest & $\mathrm{n} / \mathrm{a}$ & wild type & NA & NA & 6 \\
\hline 8426 & Right & Recurrence & $\begin{array}{l}\text { Wilms tumour } \\
\text { (diffuse anaplastic) }\end{array}$ & $\begin{array}{l}\text { c. } 584 \mathrm{~T}>\mathrm{C}: \\
\text { p.I195T }\end{array}$ & wild type & NA & NA & 54 \\
\hline
\end{tabular}

$\mathrm{NA}=$ Data not available

(a)

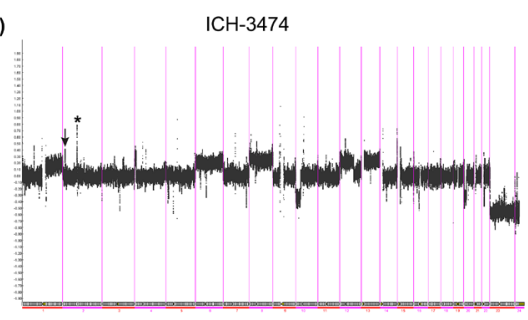

(d)

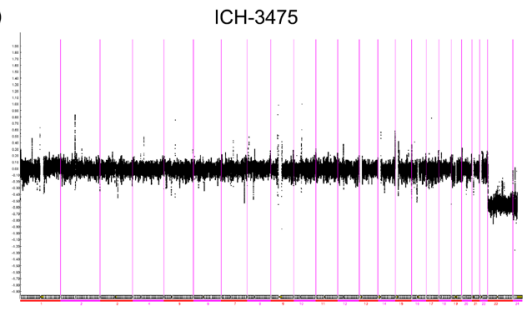

(b)

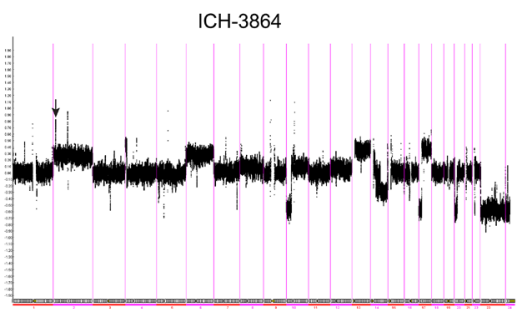

(e)

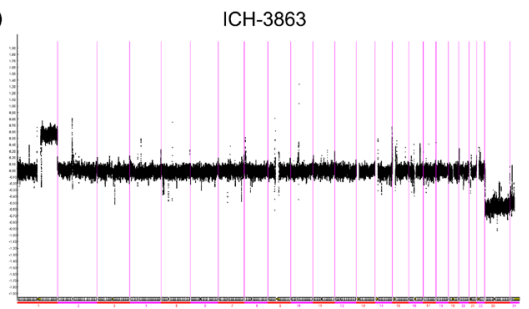

(c)

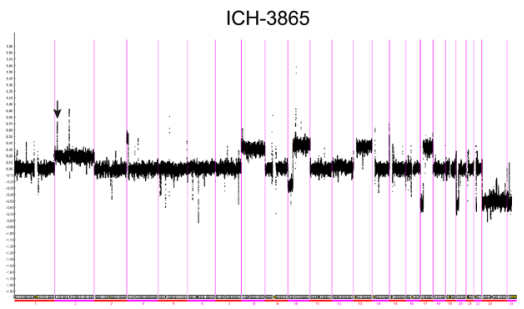

Figure 2: Copy number heterogeneity in a bilateral WT case. Affymetrix SNP 6.0 smoothed $\log 2$ ratios. (a) ICH-3474 (left, initial biopsy). (b) ICH-3864 (left, partial nephrectomy sample 1). (c) ICH-3865 (left, partial nephrectomy sample 2). (d) ICH-3475 (right, initial biopsy). (e) ICH-3863 (right, partial nephrectomy). Arrows: position of MYCN gain. x-axis: genomic position (divided by chromosome). y-axis: relative copy number ( $\log 2$ scale). Known copy number variants detected by CNV-specific probes on the SNP 6.0 array were not excluded from this analysis, and are visible as multiple focal peaks in all profiles; the most prominent peak on $2 \mathrm{p}$, labelled '*' in panel (a), corresponds to the variable $A N K R D 36 B P 2$ locus, and should not be confused with the MYCN peak. 
MYCN sequence variants (as below) showed that three of the eight P44L tumours (ICH-4788, 6613 and 8819) also had evidence of $M Y C N$ gain, while single control probes on $2 \mathrm{p}(D Y S F)$ and $2 \mathrm{q}(P A X 3)$ detected normal copy number, indicating a focal or regional event rather than whole arm or chromosome gain. ICH-7512, the A158V case, had large scale or complete gain of chromosome 2, as did one of the samples with a silent mutation, ICH8914.

\section{Germline $M Y C N$ gain in a bilateral WT case}

In a SNP array analysis of a bilateral case, a relatively focal single copy gain of $M Y C N$ was detected in both contralateral tumours. To determine if this was a germline aberration, or a somatic change (an early event in kidney development or a contralateral metastasis), copy number profiles were also obtained from the (right) normal kidney and the patient's blood DNA. Both samples harboured the region of gain, confirming that this was a germline event. Segmentation of the copy number data with OncoSNP detected a $<0.5 \mathrm{Mb}$ region of single copy gain (Figure 1, Supplementary Figure 1), spanning 98 SNP probes from rs2287273 (chr2: 15658523) to rs6748658 (chr2: 16145517), and flanked by rs2287272 (chr2: 15651846) and rs 13008990 (chr2: 16150760), the nearest probes which detected normal copy number. The region of gain contained the complete coding sequences of $M Y C N$ and $D D X 1$, and the 5 ' region of $N B A S$, and was consistent with the focal gains typically observed in WT samples in our previous SNP array study [11].

\section{Parallel Evolution of $M Y C N$ mutations and copy number aberrations in a bilateral WT case}

One of the samples in which a P44L mutation was detected by exome sequencing was taken from the right side of a second bilateral case we have previously described [36]. This case is notable for its significant intra-tumour heterogeneity on the left side (Figure 2, Supplementary Figure 2, Table 2), and for the evolution of different anaplasia-associated TP53 mutations in each contralateral tumour. We assessed codon 44 status, major copy number aberrations, and copy neutral loss of heterozygosity ( $\mathrm{LOH})$ in multiple samples taken at various time points (Table 2). For MYCN, the copy number measurements by SNP array were confirmed by MLPA (as below) in three samples (ICH 3863, ICH-3864 and ICH-3865), which gave fully concordant results. Two spatially separated samples from the initial right partial nephrectomy carried the P44L mutation, and a SNP array of one of these indicated normal MYCN copy number. There were no $M Y C N$ mutations in any other material from the right kidney (Table 2), but as previously reported [36], this tumour carried a p.I195T mutation in TP53 at relapse, consistent with its anaplastic histology; high quality DNA suitable for copy number analysis was not available for the sample at this time point.

In the left kidney, P44 was wild type in all material, including 3 tumour samples that carried the previously reported contralateral p.V173L mutation in TP53 [36]. SNP arrays were available for two of these samples and from an initial biopsy (Figure 2); all showed clear evidence of $M Y C N$ gain. Thus, in the contralateral kidneys of a single case with considerable spatial heterogeneity we observed separate MYCN aberrations (P44L on the right, copy number gain on the left) and distinct TP53 mutations (I195T on the right, V173L on the left).

\section{MYCN gain is associated with anaplastic histology and poorer outcome}

MYCN gain was measured in 293 WT cases (Supplementary Table 1) using the P380 Wilms Tumour probemix (gain threshold $=1.2$, determined empirically with reference to Affymetrix and Illumina SNP array data). A single sample with copy number loss at the $M Y C N$ locus was excluded from further analysis. Associations between histological subtype and gain were assessed by two-tailed Fisher's exact test. There was no significant association ( $\mathrm{p}>0.05$ ) between histology and $M Y C N$ gain for the blastemal, epithelial, stromal, mixed, regressive or focal anaplastic subtypes. However, for the diffuse anaplastic subtype, where 7/23 (30.4\%) samples had $M Y C N$ gain compared to $30 / 269(11.2 \%)$ in the remaining series, the association was significant $(\mathrm{p}=0.0159)$. Survival analyses factored by MYCN copy number status (gained / normal) were carried out using the Kaplan-Meier model (Figure 3); two samples with no outcome data were excluded, and two further samples from patients who died without a defined relapse event were included in the analyses of overall, but not relapse-free, survival. $M Y C N$ gain was associated with significantly poorer relapse-free $(\mathrm{p}=0.005)$ and overall $(\mathrm{p}=0.002)$ survival by the Log Rank (Mantel-Cox) test. Using the Cox Proportional Hazards model, we calculated the hazard ratios for $M Y C N$ gain as 2.443 (relapse) and 3.545 (death). However, since anaplastic histology is itself associated with poor outcome, survival analysis was also carried out with the anaplastic samples removed from the series (Figure 3). Again, the $M Y C N$ gain group had significantly poorer relapse-free $(\mathrm{p}=0.006)$ and overall $(\mathrm{p}$ $=0.003$ ) survival by the Log Rank test, with hazard ratios of 2.697 (relapse) and 4.610 (death). 11 of the 37 samples with MYCN gain (2p24.3) also had gain of the DYSF locus (control probe) on $2 \mathrm{p} 13.3$, indicating that $M Y C N$ gain is not always focal. We therefore determined whether gain of DYSF, as an example of a $2 \mathrm{p}$ locus that is distinct from $M Y C N$, is associated with a particular subtype or outcome, using the same analyses we applied to MYCN (excluding cases with DYSF loss). There was no association between 
DYSF gain and any of the histological subtypes, and no significant difference between the relapse free or overall survival of cases with gained or normal DYSF at the $\mathrm{p}<$ 0.05 level.

\section{MYCN overexpression is associated with hypomethylation of specific loci}

In a parallel study in our laboratory, we have recently completed an integrated genomic analysis of WT in which 65 samples were profiled on Affymetrix $250 \mathrm{~K}$ Nsp / SNP 6.0 arrays for copy number, Illumina HT-12 arrays for mRNA expression, and Illumina $450 \mathrm{~K}$ arrays for DNA methylation (manuscript in preparation). We therefore examined these data to determine if there is evidence of significant differential regulation of $M Y C N$ expression in this tumour series. $M Y C N$ expression levels were assessed in each of six histological subtypes (Figure 4, Supplementary Table 2). Levels of expression appeared notably higher in the high risk diffuse anaplastic (DA) and blastemal type (BT) tumours than in the four intermediate risk (IR: epithelial, stromal, mixed and regressive type) tumours examined. Univariate class comparisons (two-sample t-test) between the IR tumours (taken together as a group) and the tumours in either

(a)

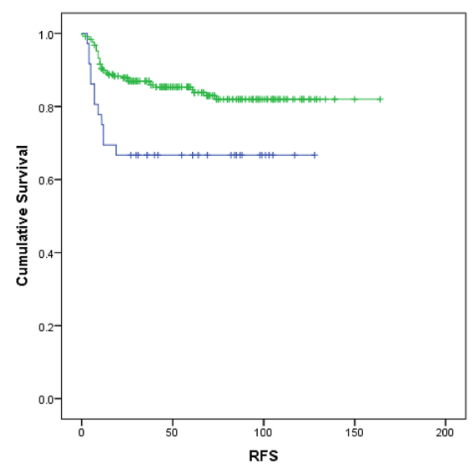

(c)

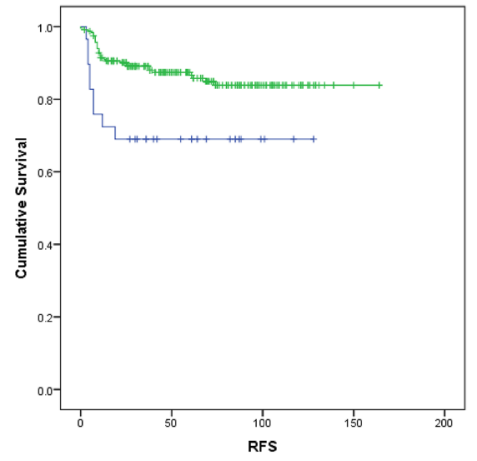

of the high risk groups identified $M Y C N$ as a relatively overexpressed gene in both DA and BT WT. When DA tumours were compared with IR tumours at the $p<0.01$ significance level, $1786 / 34339(5 \%)$ of the probes on the array detected differential expression, including both probes for MYCN (ILMN 1653761: p $=0.0001$, foldchange 2.10; ILMN_2219767: $\mathrm{p}=0.0002$, fold-change 3.34). Similarly, for BT vs IR, 2521/34339 (7\%) of probes detected differential expression, including both $M Y C N$ probes (ILMN 1653761: $\mathrm{p}=0.0019$, fold-change 1.66; ILMN_2219767: $\mathrm{p}=0.0013$, fold-change 2.87). MYCN overexpression also appeared to be associated with poorer outcome. Applying the Cox proportional hazards model to the expression data (Wald statistic, $\mathrm{p}<0.01$ ) identified 803 probes that detected genes in which overexpression was associated with poorer relapse-free survival (hazard ratio $\geq 1.5$ ), including both MYCN probes (ILMN_1653761: p $=0.0082$, hazard ratio $=1.9$; ILMN 2219767: $\mathrm{p}=0.0097$, hazard ratio $=1.5)$. To establish whether the expression patterns we observed were potentially driven by DNA methylation events or by copy number changes, we carried out Spearman rank correlation analyses across the sample series between the expression data ( $\log 2$ intensity) and either the segmented $\log 2$ copy number data, or the logit-transformed methylation value ( $\mathrm{M}$ value), using all probes with annotation that mapped them to $M Y C N$. By

(b)

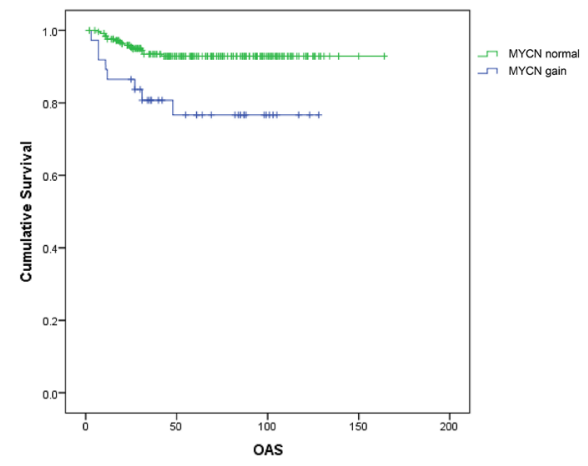

(d)

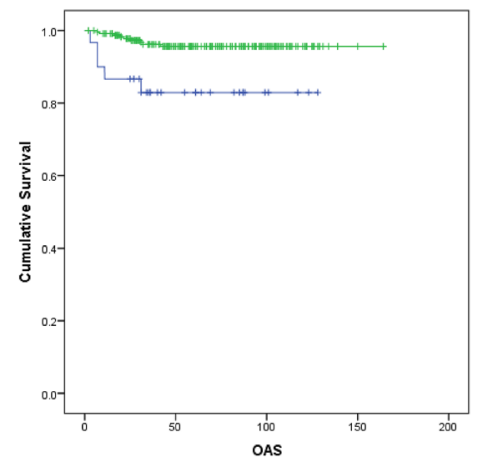

Figure 3: Survival analysis in SIOP patients with or without $M Y C N$ gain. (a) Relapse-free survival (RFS) in cases of all histologies with MYCN gain (blue) or with normal MYCN copy number (green). (b) Overall survival (OAS) in patients of all histologies. (c) Relapse-free survival in cases with diffuse anaplasia excluded. (d) Overall survival in cases with diffuse anaplasia excluded. 
this metric we detected only a weak positive correlation between $M Y C N$ expression and copy number that did not quite reach statistical significance (ILMN_1653761: rho = $0.23, \mathrm{p}=0.0672 ;$ ILMN_2219767: $\mathrm{rho}=0.24, \mathrm{p}=0.0522)$. However, we detected a strong negative correlation (rho $=-0.50$ to $-0.71, \mathrm{p}<0.0001$ ) between $M Y C N$ expression detected by both probes and methylation level at five loci probed by the $450 \mathrm{~K}$ array (Figure 5). Two of these loci (cg20431766 and $\operatorname{cg} 07083806)$ are in the intron downstream of the first $M Y C N$ coding exon, and the more 5' probe, cg20431766, is within the CpG island that spans the MYCN promoter. The other three loci (cg19623054, $\operatorname{cg} 04609952, \operatorname{cg} 25074809)$ overlap with the second coding exon. Although the methylation array includes another 18 probes that are annotated to $M Y C N$ and either overlap with the gene or are located in the intergenic region immediately upstream of its start site, none of these detected differential methylation that significantly correlated with gene expression (Spearman rho $<-0.5$ or $>0.5 ; \mathrm{p}<0.05)$.

\section{DISCUSSION}

The results presented here suggest that MYCN function in Wilms tumour is potentiated by several mechanisms. Copy number gains that included the
MYCN locus were detected in 37/292 (12.7\%) of tumours overall, and in $7 / 23$ (30.4\%) of diffuse anaplastic WTs. Relative overexpression of $M Y C N$ is associated with hypomethylation of two differentially methylated regions within the MYCN gene. 8/213 (3.8\%) of samples carried a recurrent point mutation, c. $131 \mathrm{C}>\mathrm{T}$ (p.P44L), that has been identified in neuroblastoma as an acquired somatic variant with presumed gain of function [27]. MYCN mutations had not previously been described in WT, but during the review of this manuscript another group [37] reported two further examples of the P44L mutation. We note also that our previous discovery of $F B X W 7$ aberrations in a small proportion of WTs [11] may represent an additional mechanism of $\mathrm{MYCN}$ regulation, since FBXW7 is part of a ubiquitin ligase complex that degrades MYCN.

Our results suggest that $M Y C N$ dysregulation is significantly associated with adverse outcome. $M Y C N$ gain was associated with high risk diffuse anaplastic histology, and with poorer relapse-free and overall survival, even when diffuse anaplastic cases were excluded from the analysis. This is consistent with a previous study that found an association between $M Y C N$ expression and relapse [38]. $M Y C N$ was relatively overexpressed in diffuse anaplastic and blastemal type tumours, and there was an association between expression level and poorer
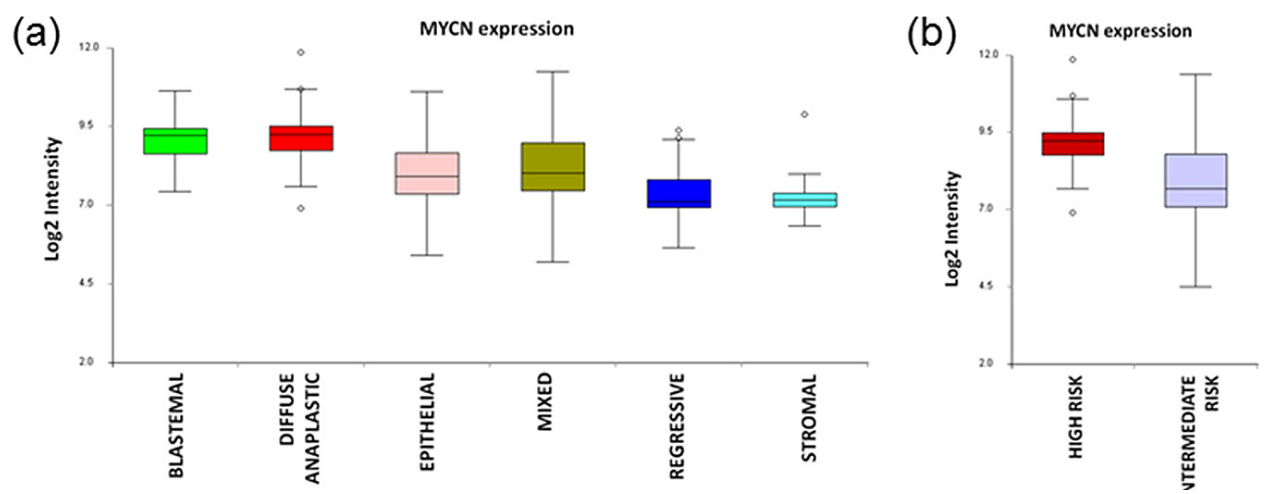

Figure 4: MYCN expression in Wilms tumour. Box plots of $M Y C N$ expression in (a) six SIOP histological WT subtypes and (b) with histologies grouped together as high risk or intermediate risk. Values are the mean log2 intensities of expression detected by both Illumina HT-12 probes within each subtype: blastemal type $(n=9$, high risk), diffuse anaplastic $(n=11$, high risk), epithelial type ( $n=9$, intermediate risk), mixed type $(n=17$, intermediate risk), regressive type $(n=10$, intermediate risk) and stromal type $(n=9$, intermediate risk). Focal anaplastics were excluded due to insufficient numbers.

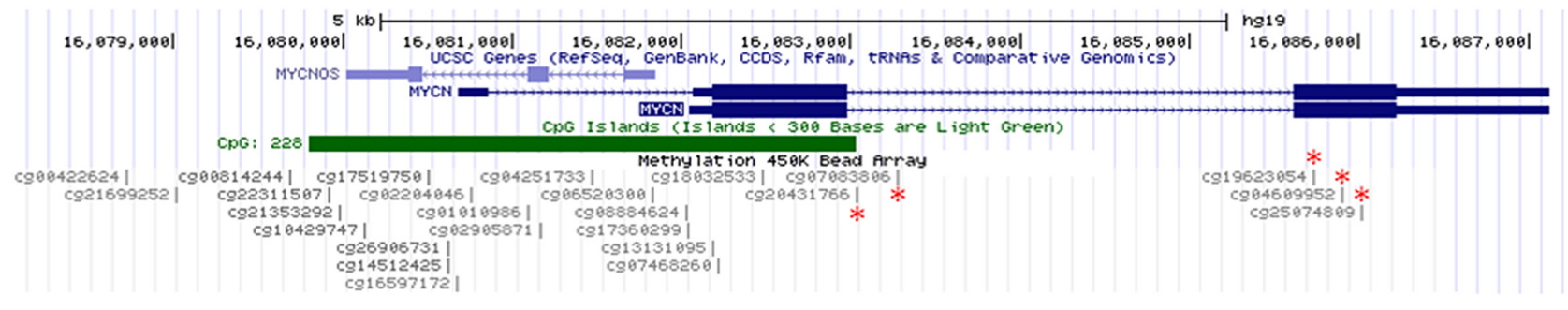

Figure 5: Illumina 450K methylation probes in the $M Y C N$ region. * = locus where expression and methylation are significantly correlated. 
relapse-free survival. However, it is unclear if all potential mechanisms of dysregulation have the same functional effect on downstream pathways or tumour behaviour. The number of P44L mutations detected to date is too small to draw firm conclusions about associations with outcome or histology. A recurrent somatic variant at a single highly conserved residue is most consistent with an activating mutation, though it has not yet been subject to a full functional analysis in WT or in neuroblastoma. We did detect one additional somatic variant, R285W, that is predicted to be deleterious, but its exact functional impact is currently unknown. Three of the P44L mutations were also associated with $M Y C N$ copy number gain. This may indicate further selection by the tumour cell for multiple copies of a variant that confers a growth advantage.

The case with $M Y C N$ mutation in one kidney and copy number gain in the other is a striking example of parallel evolution in bilateral disease. As we reported previously [36], this case also has independent contralateral TP53 mutations, albeit with apparently dissimilar timing of the mutational events. In the left kidney, $M Y C N$ gain was detected in all specimens examined (Table 2), including the initial pre-chemotherapy biopsy, while the V173L TP53 mutation was absent at initial biopsy and in a precursor lesion (nephrogenic rest). A copy number profile was not available for the nephrogenic rest, so it was not possible to determine if $M Y C N$ gain was present in the earliest phase of tumourigenesis, but it is notable that the $M Y C N$ aberration, together with the large-scale copy number changes on $10 \mathrm{p}, 20 \mathrm{p}$ and 13 that were common to all profiled samples, appear to have preceded disruption of TP53 by point mutation and $17 \mathrm{p}$ loss. In the right kidney, both genes were wild type at initial biopsy, but the MYCN P44L mutation was detected at the time of the first (partial) resection, again before any TP53 aberrations were observed. A subsequent relapse, 4 years after the original tumour was excised, carried the I195T TP53 mutation, concomitant with the development of anaplasia, but the $M Y C N$ sequence was wild type. It therefore appears that similar but independent evolutionary solutions affecting two different pathways have been selected for at different stages of the development of contralateral tumours in the same patient, with $M Y C N$ disruption the earlier event on each side. We note, however, that interpretation of this case is complicated by spatial heterogeneity, which is obviously extensive, at least at the copy number level. It is, for example, not possible to determine from our current analysis whether the relapse in the right kidney, which has a novel TP53 mutation but lacks the MYCN mutation, arose from some minority clone not sampled or undetectable in the first (partial) nephrectomy, or if the relapse itself (of which there was only a single sample) had developed significant spatial heterogeneity. It is even possible that the 'recurrence' was a novel primary tumour.

$M Y C N$ gain, even when focal, typically also results in gain of the adjacent $D D X 1$ gene. All the focal events at this locus analysed by SNP arrays in our previous study [11] had $D D X 1$ gain, as did the germline gain detected here. Recently, a similar region of germline gain encompassing both genes was detected in a patient with bilateral nephroblastomatosis and a family history of WT [39]. A genome-wide association study has also identified potential WT susceptibility loci in this commonly gained region, mapping to SNPs that flank $D D X 1$ [40]. We cannot therefore rule out a significant role for $D D X 1$ in Wilms tumour. However, our finding that $M Y C N$ is also subject to putatively activating point mutations strongly suggests that $M Y C N$ is a primary target for dysregulation at this locus.

In addition to neuroblastoma and WT, $M Y C N$ gain or amplification is now emerging as a common aberration associated with adverse outcome in multiple paediatric malignancies, including rhabdomyosarcoma [26] and medulloblastoma $[24,25]$. This raises the possibility that any novel therapies that target the MYCN pathway and prove useful in one of these tumours could be of significant value in the others. In WT, anaplastic tumours that are metastatic at presentation respond poorly to current treatment. While TP53 mutation remains the most common aberration in this group of tumours, our finding of an association between $M Y C N$ gain and anaplasia, as well as outcome, makes the MYCN pathway an attractive target for further research into new approaches to treatment.

\section{MATERIALS AND METHODS}

\section{Clinical samples}

Frozen Wilms tumour samples were obtained with informed consent and ethical approval according to national regulations from UK, German, Dutch, and Swedish centres participating in the SIOP WT 2001 clinical study and trial (2001-2011) (Supplementary Table 1). A frozen section was prepared directly or paraffinembedded from the same specimen used in nucleic acid extraction, stained with haematoxylin and eosin, and assessed for tumour content by an experienced paediatric pathologist. Only samples from WT cases treated by the standard neoadjuvant chemotherapy treatment approach were included in this study.

\section{Nucleic acid extraction}

Frozen tumour material was pulverised at liquid nitrogen temperatures using a Sartorius MikroDismembrator. Genomic DNA was prepared by standard detergent lysis and phenol-chloroform extraction methods. Total RNA was extracted using Trizol reagent (Life Technologies) according to the manufacturer's instructions. 


\section{Whole exome sequencing}

Target enrichment using the Agilent SureSelect V4+UTR system and sequencing on the Illumina HiSeq 2000 instrument were carried out by an external service provider. Data were analysed using a somatic variant detection pipeline on the UCL Computer Science HPC cluster. Sequence reads were aligned to human genome build hg19 using BWA [41]. Removal of PCR duplicates, local realignment around indels, and quality score recalibration were carried out using GATK [42] and Picard (http://picard.sourceforge.net/), according to the GATK 'best practice' recommendations. Somatic variants were detected with MuTect [43], annotated with ANNOVAR [44], and assessed in IGV [45, 46]. All MYCN variants are described with reference to the translational start codon of NCBI RefSeq cDNA NM_005378.4, corresponding to protein NP_005369.2.

\section{PCR and Sanger sequencing}

The complete coding sequence of $M Y C N$ was amplified from genomic DNA using primers: Ex2Af: 5'- GGTATTAAAACGAACGGGGC-3'; Ex2Ar: 5'-GGACTGGGCGGTGGAAC-3'; Ex2Bf: 5'- ATCCTCCAGGACTGCATGTG-3'; Ex2Br: 5'-CAGGCCAAGACATACGAGC-3'; Ex3Af: 5'- GCCGGAAGAGACAGATAAGC-3'; Ex3Ar: 5'- GATGTTGTGGTTTCTGCGAC-3'; Ex3Bf: 5'- CCACCAGCAGCACAACTATG-3'; Ex3Br: 5'-TACTGCCCACCCAGAGCC-3'. PCR products were sequenced using the $\mathrm{ABI}$ BigDye cycle sequencing kit on an ABI Prism 3100 Genetic Analyzer. Variants were detected and assessed with GeneScreen [47] with reference to the hg19 reference sequence.

\section{MLPA}

MLPA was performed according to the manufacturer's instructions using the P380 Wilms Tumour probemix, developed by MRC-Holland in association with our laboratory. This probemix includes 3 probes for $M Y C N$, a DYSF control probe on $2 \mathrm{p}$ outside the common region of genomic gain previously observed on SNP arrays, a $P A X 3$ control probe on $2 \mathrm{q}$, further test probes to other loci of interest in the Wilms tumour genome, and 9 reference probes to loci on chromosomes 3, 5, 15, 19 and 21 found to have comparatively stable copy number in previous Wilms tumour microarray experiments. Since MYCN binding sites are distributed throughout the genome, we reasoned that the most biologically relevant measurement of $M Y C N$ status was its copy number relative to the genomic baseline copy number. All copy number measurements were therefore made with respect to the
9 reference probes; the $D Y S F$ and $P A X 3$ probes served only to determine whether any $M Y C N$ gain observed was in the context of larger scale gain of $2 p$ or of the whole chromosome.

\section{Methylation arrays}

DNA methylation profiling was carried out according to the manufacturer's instructions using the Zymo EZ DNA Methylation kit kit and Illumina Infinium HumanMethylation450 BeadChip. Arrays were run and scanned at the UCL Genomics ICH Microarray facility. Data were normalised and analysed using the Bioconductor [48] packages minfi [49] and limma [50].

\section{Expression arrays}

Expression profiling was carried out on the Illumina HumanHT-12 v3 Expression BeadChip at the UCL Genomics ICH Microarray facility, according to the manufacturer's instructions. Data were normalised and analysed using the lumi [51] Bioconductor package and BRB-ArrayTools [52].

\section{SNP arrays}

DNA samples were profiled on Affymetrix Human Mapping 250K Nsp or Genome-Wide Human SNP Array 6.0 arrays at UCL Genomics, UK or AROS Applied Biotechnology A/S, Denmark. Copy number and LOH analysis was carried out using the Affymetrix Genotyping Console, using HapMap reference samples, and visualised in CGH Explorer [53] or IGV [45, 46]. Samples from a single case with germline $M Y C N$ gain were profiled on the Illumina HumanCytoSNP-12 BeadChip, and analysed with Illumina GenomeStudio and OncoSNP [54]. Raw data are available from the authors on request.

\section{Survival analysis}

Survival analyses were carried out in IBM SPSS 21 using the Kaplan-Meier model, with the Log Rank test for equality of the survival distributions. Hazard ratios were determined using the Cox Proportional Hazards model.

\section{ACKNOWLEDGEMENTS}

The authors would like to thank all of the staff at the clinical treatment centres in the UK, Republic of Ireland, Germany, Sweden and the Netherlands who enrolled patients on the SIOP WT 2001 trial and study and collected frozen tumour for the biological studies. We thank all the families who donated samples, and the CCLG tissue bank for access to UK samples. Some analyses were performed 
using BRB-ArrayTools developed by Dr. Richard Simon and the BRB-ArrayTools Development Team. The P380 Wilms tumour probemix was developed in conjunction with Dr Suvi Savola, MRC Holland- Amsterdam.

\section{FUNDING}

The Pritchard-Jones laboratory is funded by Cancer Research UK (C1188/A4614), Great Ormond Street Hospital (GOSH) Children's Charity and Children with Cancer (11MH16). KPJ is part supported by the NIHR GOSH UCL Biomedical Research Centre. The Gessler laboratory is funded by grants from the DFG (Ge539/121), the Wilhelm-Sander-Stiftung and the Competence Network Paediatric Oncology and Haematology.

\section{CONFLICTS OF INTEREST}

The authors declare no conflict of interest.

\section{Foot note}

Jan de Kraker deceased (chief investigator of the SIOPWT2001 trial, who sadly passed away during the conduct of the study).

\section{REFERENCES}

1. Bonetta L, Kuehn SE, Huang A, Law DJ, Kalikin LM, Koi M, Reeve AE, Brownstein BH, Yeger H, Williams BR and et al. Wilms tumor locus on $11 \mathrm{p} 13$ defined by multiple $\mathrm{CpG}$ island-associated transcripts. Science. 1990; 250(4983):994997.

2. Call KM, Glaser T, Ito CY, Buckler AJ, Pelletier J, Haber DA, Rose EA, Kral A, Yeger H, Lewis WH and et al. Isolation and characterization of a zinc finger polypeptide gene at the human chromosome 11 Wilms' tumor locus. Cell. 1990; 60(3):509-520.

3. Gessler M, Poustka A, Cavenee W, Neve RL, Orkin SH and Bruns GA. Homozygous deletion in Wilms tumours of a zinc-finger gene identified by chromosome jumping. Nature. 1990; 343(6260):774-778.

4. Haber DA, Buckler AJ, Glaser T, Call KM, Pelletier J, Sohn RL, Douglass EC and Housman DE. An internal deletion within an 11 p13 zinc finger gene contributes to the development of Wilms' tumor. Cell. 1990; 61(7):12571269 .

5. Huang A, Campbell CE, Bonetta L, McAndrews-Hill MS, Chilton-MacNeill S, Coppes MJ, Law DJ, Feinberg AP, Yeger $\mathrm{H}$ and Williams BR. Tissue, developmental, and tumor-specific expression of divergent transcripts in Wilms tumor. Science. 1990; 250(4983):991-994.

6. Rose EA, Glaser T, Jones C, Smith CL, Lewis WH, Call KM, Minden M, Champagne E, Bonetta L, Yeger H and et al. Complete physical map of the WAGR region of $11 \mathrm{p} 13$ localizes a candidate Wilms' tumor gene. Cell. 1990; 60(3):495-508.

7. Koesters R, Ridder R, Kopp-Schneider A, Betts D, Adams V, Niggli F, Briner J and von Knebel Doeberitz M. Mutational activation of the beta-catenin proto-oncogene is a common event in the development of Wilms' tumors. Cancer Res. 1999; 59(16):3880-3882.

8. Maiti S, Alam R, Amos CI and Huff V. Frequent association of beta-catenin and WT1 mutations in Wilms tumors. Cancer Res. 2000; 60(22):6288-6292.

9. Rivera MN, Kim WJ, Wells J, Driscoll DR, Brannigan BW, Han M, Kim JC, Feinberg AP, Gerald WL, Vargas SO, Chin L, Iafrate AJ, Bell DW and Haber DA. An X chromosome gene, WTX, is commonly inactivated in Wilms tumor. Science. 2007; 315(5812):642-645.

10. Bardeesy N, Falkoff D, Petruzzi MJ, Nowak N, Zabel B, Adam M, Aguiar MC, Grundy P, Shows T and Pelletier J. Anaplastic Wilms' tumour, a subtype displaying poor prognosis, harbours p53 gene mutations. Nat Genet. 1994; 7(1):91-97.

11. Williams RD, Al-Saadi R, Chagtai T, Popov S, Messahel B, Sebire N, Gessler M, Wegert J, Graf N, Leuschner I, Hubank M, Jones C, Vujanic G and Pritchard-Jones K. Subtype-specific FBXW7 mutation and MYCN copy number gain in Wilms' tumor. Clinical cancer research : an official journal of the American Association for Cancer Research. 2010; 16(7):2036-2045.

12. White GR, Kelsey AM, Varley JM and Birch JM. Somatic glypican 3 (GPC3) mutations in Wilms' tumour. Br J Cancer. 2002; 86(12):1920-1922.

13. Scott RH, Douglas J, Baskcomb L, Huxter N, Barker K, Hanks S, Craft A, Gerrard M, Kohler JA, Levitt GA, Picton S, Pizer B, Ronghe MD, Williams D, Cook JA, Pujol P, et al. Constitutional 11 p15 abnormalities, including heritable imprinting center mutations, cause nonsyndromic Wilms tumor. Nat Genet. 2008; 40(11):1329-1334.

14. Torrezan GT, Ferreira EN, Nakahata AM, Barros BD, Castro MT, Correa BR, Krepischi AC, Olivieri EH, Cunha IW, Tabori U, Grundy PE, Costa CM, de Camargo B, Galante PA and Carraro DM. Recurrent somatic mutation in DROSHA induces microRNA profile changes in Wilms tumour. Nat Commun. 2014; 5:4039.

15. Schumacher V, Schneider S, Figge A, Wildhardt G, Harms D, Schmidt D, Weirich A, Ludwig R and RoyerPokora B. Correlation of germ-line mutations and twohit inactivation of the WT1 gene with Wilms tumors of stromal-predominant histology. Proc Natl Acad Sci U S A. 1997; 94(8):3972-3977.

16. Hing S, Lu YJ, Summersgill B, King-Underwood L, Nicholson J, Grundy P, Grundy R, Gessler M, Shipley J and Pritchard-Jones K. Gain of 1q is associated with adverse outcome in favorable histology Wilms' tumors. Am J Pathol. 2001; 158(2):393-398. 
17. Natrajan R, Williams RD, Hing SN, Mackay A, Reis-Filho JS, Fenwick K, Iravani M, Valgeirsson H, Grigoriadis A, Langford CF, Dovey O, Gregory SG, Weber BL, Ashworth A, Grundy PE, Pritchard-Jones K, et al. Array CGH profiling of favourable histology Wilms tumours reveals novel gains and losses associated with relapse. J Pathol. 2006; 210(1):49-58.

18. Grundy PE, Breslow NE, Li S, Perlman E, Beckwith JB, Ritchey ML, Shamberger RC, Haase GM, D’Angio GJ, Donaldson M, Coppes MJ, Malogolowkin M, Shearer P, Thomas PR, Macklis R, Tomlinson G, et al. Loss of heterozygosity for chromosomes $1 \mathrm{p}$ and $16 \mathrm{q}$ is an adverse prognostic factor in favorable-histology Wilms tumor: a report from the National Wilms Tumor Study Group. Journal of clinical oncology : official journal of the American Society of Clinical Oncology. 2005; 23(29):73127321.

19. McQuaid S and O'Meara A. N-myc oncogene amplification in paediatric tumours. Ir J Med Sci. 1990; 159(6):172-174.

20. Norris MD, Brian MJ, Vowels MR and Stewart BW. N-myc amplification in Wilms' tumor. Cancer Genet Cytogenet. 1988; 30(1):187-189.

21. Schaub R, Burger A, Bausch D, Niggli FK, Schafer BW and Betts DR. Array comparative genomic hybridization reveals unbalanced gain of the MYCN region in Wilms tumors. Cancer Genet Cytogenet. 2007; 172(1):61-65.

22. Williams RD, Al-Saadi R, Natrajan R, Mackay A, Chagtai T, Little S, Hing SN, Fenwick K, Ashworth A, Grundy P, Anderson JR, Dome JS, Perlman EJ, Jones C and PritchardJones K. Molecular profiling reveals frequent gain of MYCN and anaplasia-specific loss of $4 \mathrm{q}$ and $14 \mathrm{q}$ in Wilms tumor. Genes, chromosomes \& cancer. 2011; 50(12):982995.

23. Perotti D, Spreafico F, Torri F, Gamba B, D'Adamo P, Pizzamiglio S, Terenziani M, Catania S, Collini P, Nantron M, Pession A, Bianchi M, Indolfi P, D’Angelo P, FossatiBellani F, Verderio P, et al. Genomic profiling by wholegenome single nucleotide polymorphism arrays in Wilms tumor and association with relapse. Genes, chromosomes \& cancer. 2012; 51(7):644-653.

24. Pfister S, Remke M, Benner A, Mendrzyk F, Toedt G, Felsberg J, Wittmann A, Devens F, Gerber NU, Joos S, Kulozik A, Reifenberger G, Rutkowski S, Wiestler OD, Radlwimmer B, Scheurlen W, et al. Outcome prediction in pediatric medulloblastoma based on DNA copy-number aberrations of chromosomes 6q and 17q and the MYC and MYCN loci. Journal of clinical oncology : official journal of the American Society of Clinical Oncology. 2009; 27(10):1627-1636.

25. Aldosari N, Bigner SH, Burger PC, Becker L, Kepner JL, Friedman HS and McLendon RE. MYCC and MYCN oncogene amplification in medulloblastoma. A fluorescence in situ hybridization study on paraffin sections from the Children's Oncology Group. Archives of pathology \& laboratory medicine. 2002; 126(5):540-544.
26. Williamson D, Lu YJ, Gordon T, Sciot R, Kelsey A, Fisher C, Poremba C, Anderson J, Pritchard-Jones K and Shipley J. Relationship between MYCN copy number and expression in rhabdomyosarcomas and correlation with adverse prognosis in the alveolar subtype. Journal of clinical oncology : official journal of the American Society of Clinical Oncology. 2005; 23(4):880-888.

27. Pugh TJ, Morozova O, Attiyeh EF, Asgharzadeh S, Wei JS, Auclair D, Carter SL, Cibulskis K, Hanna M, Kiezun A, Kim J, Lawrence MS, Lichenstein L, McKenna A, Pedamallu CS, Ramos AH, et al. The genetic landscape of high-risk neuroblastoma. Nat Genet. 2013; 45(3):279-284.

28. Forbes SA, Tang G, Bindal N, Bamford S, Dawson E, Cole C, Kok CY, Jia M, Ewing R, Menzies A, Teague JW, Stratton MR and Futreal PA. COSMIC (the Catalogue of Somatic Mutations in Cancer): a resource to investigate acquired mutations in human cancer. Nucleic Acids Res. 2010; 38(Database issue):D652-657.

29. Jones DT, Jager N, Kool M, Zichner T, Hutter B, Sultan M, Cho YJ, Pugh TJ, Hovestadt V, Stutz AM, Rausch T, Warnatz HJ, Ryzhova M, Bender S, Sturm D, Pleier $\mathrm{S}$, et al. Dissecting the genomic complexity underlying medulloblastoma. Nature. 2012; 488(7409):100-105.

30. TCGA. Comprehensive genomic characterization defines human glioblastoma genes and core pathways. Nature. 2008; 455(7216):1061-1068.

31. Wu J, Jiao Y, Dal Molin M, Maitra A, de Wilde RF, Wood LD, Eshleman JR, Goggins MG, Wolfgang CL, Canto MI, Schulick RD, Edil BH, Choti MA, Adsay V, Klimstra DS, Offerhaus GJ, et al. Whole-exome sequencing of neoplastic cysts of the pancreas reveals recurrent mutations in components of ubiquitin-dependent pathways. Proc Natl Acad Sci U S A. 2011; 108(52):21188-21193.

32. Finn RD, Bateman A, Clements J, Coggill P, Eberhardt RY, Eddy SR, Heger A, Hetherington K, Holm L, Mistry J, Sonnhammer EL, Tate J and Punta M. Pfam: the protein families database. Nucleic Acids Res. 2014; 42(Database issue):D222-230.

33. Kumar P, Henikoff S and Ng PC. Predicting the effects of coding non-synonymous variants on protein function using the SIFT algorithm. Nat Protoc. 2009; 4(7):1073-1081.

34. Adzhubei I, Jordan DM and Sunyaev SR. Predicting functional effect of human missense mutations using PolyPhen-2. Curr Protoc Hum Genet. 2013; Chapter 7:Unit7 20.

35. Abecasis GR, Auton A, Brooks LD, DePristo MA, Durbin RM, Handsaker RE, Kang HM, Marth GT and McVean GA. An integrated map of genetic variation from 1,092 human genomes. Nature. 2012; 491(7422):56-65.

36. Popov SD, Vujanic GM, Sebire NJ, Chagtai T, Williams R, Vaidya S and Pritchard-Jones K. Bilateral wilms tumor with TP53-related anaplasia. Pediatr Dev Pathol. 2013; 16(3):217-223.

37. Rakheja D, Chen KS, Liu Y, Shukla AA, Schmid V, Chang 
TC, Khokhar S, Wickiser JE, Karandikar NJ, Malter JS, Mendell JT and Amatruda JF. Somatic mutations in DROSHA and DICER1 impair microRNA biogenesis through distinct mechanisms in Wilms tumours. Nat Commun. 2014; 2:4802.

38. Wittmann S, Wunder C, Zirn B, Furtwangler R, Wegert J, Graf $\mathrm{N}$ and Gessler M. New prognostic markers revealed by evaluation of genes correlated with clinical parameters in Wilms tumors. Genes, chromosomes \& cancer. 2008; 47(5):386-395.

39. Fievet A, Belaud-Rotureau MA, Dugay F, Abadie C, Henry C, Taque S, Andrieux J, Guyetant S, Robert M, Dubourg C, Edan C, Rioux-Leclercq N, Odent S and Jaillard S. Involvement of germline DDX1-MYCN duplication in inherited nephroblastoma. Eur J Med Genet. 2013; 56(12):643-647.

40. Turnbull C, Perdeaux ER, Pernet D, Naranjo A, Renwick A, Seal S, Munoz-Xicola RM, Hanks S, Slade I, Zachariou A, Warren-Perry M, Ruark E, Gerrard M, Hale J, Hewitt M, Kohler J, et al. A genome-wide association study identifies susceptibility loci for Wilms tumor. Nat Genet. 2012; 44(6):681-684.

41. Li H and Durbin R. Fast and accurate short read alignment with Burrows-Wheeler transform. Bioinformatics. 2009; 25(14):1754-1760.

42. McKenna A, Hanna M, Banks E, Sivachenko A, Cibulskis K, Kernytsky A, Garimella K, Altshuler D, Gabriel S, Daly $\mathrm{M}$ and DePristo MA. The Genome Analysis Toolkit: a MapReduce framework for analyzing next-generation DNA sequencing data. Genome Res. 2010; 20(9):1297-1303.

43. Cibulskis K, Lawrence MS, Carter SL, Sivachenko A, Jaffe D, Sougnez C, Gabriel S, Meyerson M, Lander ES and Getz G. Sensitive detection of somatic point mutations in impure and heterogeneous cancer samples. Nat Biotechnol. 2013; 31(3):213-219.

44. Wang K, Li M and Hakonarson H. ANNOVAR: functional annotation of genetic variants from high-throughput sequencing data. Nucleic Acids Res. 2010; 38(16):e164.

45. Robinson JT, Thorvaldsdottir H, Winckler W, Guttman M, Lander ES, Getz G and Mesirov JP. Integrative genomics viewer. Nat Biotechnol. 2011; 29(1):24-26.

46. Thorvaldsdottir H, Robinson JT and Mesirov JP. Integrative Genomics Viewer (IGV): high-performance genomics data visualization and exploration. Brief Bioinform. 2013; 14(2):178-192.

47. Carr IM, Camm N, Taylor GR, Charlton R, Ellard S, Sheridan EG, Markham AF and Bonthron DT. GeneScreen: a program for high-throughput mutation detection in DNA sequence electropherograms. J Med Genet. 2011; 48(2):123-130.

48. Gentleman RC, Carey VJ, Bates DM, Bolstad B, Dettling M, Dudoit S, Ellis B, Gautier L, Ge Y, Gentry J, Hornik K, Hothorn T, Huber W, Iacus S, Irizarry R, Leisch F, et al. Bioconductor: open software development for computational biology and bioinformatics. Genome Biol. 2004; 5(10):R80.

49. Aryee MJ, Jaffe AE, Corrada-Bravo H, Ladd-Acosta C, Feinberg AP, Hansen KD and Irizarry RA. Minfi: A flexible and comprehensive Bioconductor package for the analysis of Infinium DNA Methylation microarrays. Bioinformatics. 2014.

50. Smith GK. (2005). Limma: linear models for microarray data. Bioinformatics and Computational Biology Solutions using R and Bioconductor: Springer, New York), pp. $397-$ 420 .

51. Du P, Kibbe WA and Lin SM. lumi: a pipeline for processing Illumina microarray. Bioinformatics. 2008; 24(13):1547-1548.

52. Simon R, Lam A, Li MC, Ngan M, Menenzes S and Zhao Y. Analysis of gene expression data using BRB-ArrayTools. Cancer Inform. 2007; 3:11-17.

53. Lingjaerde OC, Baumbusch LO, Liestol K, Glad IK and Borresen-Dale AL. CGH-Explorer: a program for analysis of array-CGH data. Bioinformatics. 2005; 21(6):821-822.

54. Yau C, Mouradov D, Jorissen RN, Colella S, Mirza G, Steers G, Harris A, Ragoussis J, Sieber O and Holmes CC. A statistical approach for detecting genomic aberrations in heterogeneous tumor samples from single nucleotide polymorphism genotyping data. Genome Biol. 2010; 11(9):R92. 